\title{
THE 2007 HENNIPMAN PRIZE
}

\section{REPORT OF THE SELECTION COMMITTEE}

We were pleased to identify three articles in the 2005-2006 volumes of De Economist that were potentially prize-winning. Articles were assessed on the basis of four criteria: originality (of the research question and of the approach), methodology (appropriateness and sophistication of method), presentation (accessibility, clarity), and relevance for society.

Two of the articles show that, in a variety of settings, accounting is and should be at the core of economic analysis. One of these was "Generational accounting, solidarity and pension losses" by Coen N. Teulings en Casper G. De Vries (Vol. 154, No.1, pp. 63-83). Teulings and De Vries carefully build on generational accounting models of Auerbach and Kotlikof to analyze the changes in the wealth composition of pension funds, and their bearing on intergenerational solidarity. A second one was the article "Post-Enron implicit audit reporting standards: Sifting through the evidence" by the Belgian economists Piet Sercu, Heidi vander Bauwhede, and Marleen Willekens (Vol. 154, No. 3, pp. 389-403). Sercu, Vander Bauwhede, and Willekens take the Enron scandal as a starting point of an original empirical analysis of issuing non-clean opinions on financial statements by auditors. The Selection Committee awards honorable mentions to both these articles.

The article that the Selection Committee considered best is titled "Retail payments in the Netherlands: Facts and theory" (Vol. 154, No. 3, pp. 354372). Its author - and winner of the 2007 Hennipman Prize - is Wilko Bolt, researcher at the Dutch Central Bank. The article by Wilko Bolt scores very high on all criteria mentioned. While it builds on earlier work of Bolt with Tieman, the topic - pricing in modern electronic payment markets - is original. The Netherlands and other countries experienced a rapid shift from cash and paper-based payment methods towards electronic payments. Payment pricing is a complex issue because of strong network externalities. The paper develops a rigorous theoretical model that exploits recent insights into pricing in two-sided markets. The model is supported by stylized empirical facts on network pricing, and considers both behavioral and welfare aspects of pricing outcomes. An important conclusion is that traditional antitrust logic is not readily applicable in two-sided markets; in these markets pricing is not just a question of choosing the right price level but rather of choosing the right price structure.

The combination of originality of topic, academic rigor that combines theory and data, relevance for society, and clarity of style, makes this paper a more than worthy addition to the list of Hennipman Prize winning papers. 
Open Access This article is distributed under the terms of the Creative Commons Attribution Noncommercial License which permits any noncommercial use, distribution, and reproduction in any medium, provided the original author(s) and source are credited.

HARRY GARRETSEN PETER KOOREMAN TON VAN SCHAIK 